\title{
The Sheathed Flagellum of Pseudomonas stizolobii
}

\author{
By J. A. FUERST AND A. C. HAYWARD \\ Department of Microbiology, University of Queensland, \\ Brisbane, Australia 4006 \\ (Accepted for publication I6 June 1969) \\ SUMMARY
}

\begin{abstract}
Organisms of two strains of Pseudomonas stizolobii possessed one polar flagellum of unusual thickness. Negative-contrast staining and ultrathin sectioning indicated that the flagella are sheathed and are comparable in structure to the sheathed flagella described in Vibrio and Bdellovibrio. In some instances, flagella displayed sheath and core structure after negative constrast staining. Distal 'tubules' and 'knobs' apparently consisting entirely of sheath material were also seen. The thickness of the sheath, which in section consisted of an outer dense component and an inner lighter component, was similar to that of the outer double track membrane of the cell wall.
\end{abstract}

\section{INTRODUCTION}

During the examination of a collection of species of Pseudomonas for the presence of fimbria-like appendages (Fuerst \& Hayward, 1969), unusual polar flagella were seen on Pseudomonas stizolobii (Wolf) Stapp, 1935. This species is a plant pathogen causing a disease of the leaves and stems of mainly leguminous plants (Burkholder, I957; Rothwell \& Hayward, 1964). Whereas flagella of most bacteria are 120 to I50 $\AA$ in diameter and, under the electron microscope at high resolution, preparations of negatively stained material exhibit a helical aggregate of globular subunits, (Joys, 1968; Doetsch \& Hageage, 1968), the flagella of $P$. stizolobii were of greater thickness and lacked the substructure characteristic of unsheathed bacterial flagella. Our aim was to determine by electron microscopic techniques the nature of the flagellum of $P$. stizolobii and to compare it with the sheathed flagella which are known to occur in a very few genera of Gram-positive and Gram-negative bacteria.

\section{METHODS}

Organisms and media. Pseudomonas stizolobii NCPPB 450 and P. stizolobii strain $0268 \mathrm{~A}$, as listed by Fuerst \& Hayward (1969), were grown at $28^{\circ}$ in either motility medium (Difco bacto peptone, 5.0 g.; glycerol, 5.0 g.; $\mathrm{MgSO}_{4} \cdot 7 \mathrm{H}_{2} \mathrm{O}, 0.25 \mathrm{~g}$.; $\mathrm{K}_{2} \mathrm{HPO}_{4}$, 0.5 g.; Difco agar, 3.0 g.; distilled water, I 1.), peptone yeast extract broth (see Fuerst \& Hayward, 1969), or glucose peptone yeast extract broth (glucose, I g.; peptone yeast extract broth, I00 $\mathrm{ml}$.).

Organisms not to be treated with reagents were carried through two $72 \mathrm{hr}$ serial subcultures in Craigie tubes of motility medium and 5 or 8 serial subcultures of variable duration in $6 \times \frac{1}{2}$ in., tubes containing $5 \mathrm{ml}$. peptone yeast extract broth. Organisms to be treated with various reagents (including distilled water controls) were 
grown in tubes of peptone yeast extract broth for $70 \mathrm{hr}$ or tubes of glucose peptone yeast extract broth for $20 \mathrm{hr}$. Organisms for ultrathin sectioning were grown in $100 \mathrm{ml}$. medical flats containing $10 \mathrm{ml}$. of glucose peptone yeast extract broth and incubated for $26 \mathrm{hr}$ on their wide sides.

Initial inocula in all cases were from stock agar slopes. Purity checks were performed on all cultures examined by plating out from washed cell suspensions.

Negative contrast staining of untreated flagella. Cells were harvested by centrifugation and washed once in sterile distilled water before resuspension in the wash fluid. A I $\%$ solution of sodium phosphotungstate $(\mathrm{pH} 7.0$ or 7.3$)$ containing bovine plasma albumin to $0.03 \%$ was employed as a negative contrast stain. Negative contrast preparations were made by applying drops of washed suspension and negative contrast stain to carbon-coated copper grids as described by Fuerst \& Hayward (1969).

Treatments of flagella with reagents and negative contrast staining following treatment. Flagellated cells were treated with various reagents according to a modification of the procedure of Follett \& Gordon (I963). Unlike Follett \& Gordon (I963), cells were not fixed with formalin before treatment and ammonium molybdate was not used as a negative contrast stain. In addition Follett \& Gordon in all cases treated cells first with a I \% potassium iodide (KI.) solution before treatment with other reagents. Although a pretreatment with $\mathrm{I} \% \mathrm{KI}$. was included in some cases, this treatment was often omitted because it was not known what effect the potassium iodide itself might have on flagellar structure.

Carbon-coated grids were floated on top of washed cell suspensions. The grids were then floated on a number of wash solutions and reagents. Treatments with $\mathrm{N} / 100 \mathrm{HCl}(\mathrm{pH} \mathrm{2.2}), 6 \mathrm{M}$-urea, $10^{-3} \mathrm{M}$-sodium ethylenediaminetetra-acetic acid $\left(\mathrm{Na}_{2}\right.$ EDTA) and $0.05 \%$ phenol were interpolated between two distilled water washes. Negative contrast stain was applied by floating grids from the second distilled water wash on top of a I \% sodium phosphotungstate solution ( $\mathrm{pH} 7.4$ ) containing $0.03 \%$ bovine plasma albumin, removing excess fluid and placing in the microscope specimen chamber while still wet. The time of exposure to $6 \mathrm{M}$-urea was much shorter than that used by Follett \& Gordon (1963) since, if longer times were used, no cells could be found adhering to the grid after such treatment. This may well have affected results and similar qualifications may apply to treatments with phenol and $\mathrm{Na}_{2}$ EDTA, which were also necessarily short.

Ultrathin-sectioning. Procedures used for obtaining ultrathin sections were those used by Fuerst \& Hayward (I969).

Electron microscopy. A Siemens Elmiskop IA was used at accelerating voltages of 80 or $100 \mathrm{kV}$.

\section{RESULTS}

\section{Negative contrast staining}

Both strains of Pseudomonas stizolobii possessed one polar flagellum per cell. The cells were usually bullet shaped, being pointed at the flagellate pole and rounded at the aflagellate pole (P1. I, fig. 2). The tip of the flagellum as seen in untreated preparations was most commonly even, but occasionally an irregular appendage appeared to extend from the tip (Pl. I, fig. 2). The typical appearance of intact flagella is seen in Pl. I, fig. I. A cell of strain NCPPB 450 displays a flagellum of diameter 250 to $286 \AA$. The tip of the flagellum is rounded and no substructure of any kind is evident, although 
untreated flagella which displayed core and sheath were seen in some cases. An enlarged portion of a flagellum of strain $0268 \mathrm{~A}$ is shown in P1. 2, fig. 3; the diameter ( 262 to 3 I I $\AA$ ) is similar to that of strain NCPPB 450 , the tip is rounded and there is a lack of substructure.

Chemical treatments known to enhance the contrast between the core and sheath of vibrio flagella (Follett \& Gordon, 1963) were applied to some preparations of Pseudomonas stizolobii prior to negative contrast staining. In other cases cells were treated with solutions of the disodium salt of ethylenediaminetetra-acetic acid $\left(\mathrm{Na}_{2} \mathrm{EDTA}\right)$ or with phenol, also in the hope of delineating sheath and core. These reagents, among others, were shown by Varon \& Shilo (1968) to inhibit the motility of Bdellovibrio bacteriovorus, an organism with a single polar sheathed flagellum. They postulated that this inhibition might be connected with the sheathed flagellum structure.

After potassium iodide treatment alone prior to negative staining, delineation of sheath and core structure was seen in some cases, and the flagella were in some instances unusually thick. Thin, irregularly folded 'tubules' were often seen at the distal ends of the flagella. In Pl. 2, fig. 4 an enlarged portion of a flagellum of strain NCPPB 450 is shown after potassium iodide treatment and treatment with $\mathrm{N} / \mathrm{IOO} \mathrm{HCl}$ solution prior to negative staining. The flagellum is 225 to $295 \AA$ in diameter and displays core and sheath. Two dark lines traverse the interior of the flagellum. If only the outer light portions on both sides of the dark lines are taken to represent sheath material, then the sheath is 46 to $78 \AA$ and the core is I 30 to I $55 \AA$ in diameter. Plate 4, fig. 7 shows a flagellum after treatment with urea, and serves as a general example of the 'irregular tubule' and 'knob' appearance. The main portion of the flagellum in this micrograph is 280 to $3 I 2 \AA$ in diameter. The 'tubule' at its distal end appears to be continuous with the outer parts of the flagellum, and is 100 to $166 \AA$ in diameter. The round ' $k n o b$ ' appears to be continuous with the 'tubule' and is $425 \AA$ in diameter.

Treatments with urea or hydrochloric acid did not result in appearances similar to those of flagella of Vibrio species (Follett \& Gordon, 1963) and Bdellovibrio bacteriovorus (Seidler \& Starr, 1968) after similar treatments. This may have been due to the different times of exposure to the reagents used in this study, or to differences in relative stabilities of the sheaths of different species.

Core and sheath delineation and distal 'tubules' and 'knobs' were also seen in phenol- and EDTA-treated preparations (see Pl. 3, fig. 5, 6). In P1. 3, fig. 6 the more proximal part of the flagellum does not show core and sheath structure, but towards the distal portion near to the 'tubule' and ' $k$ nob' such a structure is more clearly seen. The core is 125 to I50 $\AA$ wide where there is a well-defined core and sheath while the sheath material on either side is 50 to $75 \AA$ in diameter.

\section{Appearance of sheathed flagella in ultrathin sections}

Ultrathin sections of cells of Pseudomonas stizolobii in certain instances displayed what appeared to be flagella in longitudinal section (Pl.4, fig. 8, 9). The sheath appears to be composed of at least an outer dense component and an inner light component, and there are indications of another dense line bounding the inner light component, particularly in $\mathrm{Pl}$. 4, fig. 8. In Pl. 4, fig. 8, the sheath is 42 to $58 \AA$ wide while the core is Ioo to I $33 \AA$ wide. Although no obvious continuity between the outer layers of the cell wall and the sheath could be discerned in these sections, the outer triple-layered 
membrane around the sectioned cells is comparable in thickness to the sheath bounding the flagellar core.

\section{DISCUSSION}

Sheathed flagella are known to occur in few species of bacteria, including Gramnegative and Gram-positive organisms and organisms with peritrichous as well as those with polar flagella. Present information is summarized in Table $\mathrm{I}$. The sheathed flagella of species of Vibrio and Bdellovibrio bacteriovorus have been most fully studied. The sheathed flagellum of Pseudomonas stizolobii resembles those of Vibrio and Bdellovibrio in diameter and structure. It is of interest to determine whether $P$. stizolobii has other characters in common with Vibrio. However, there is little evidence to support such a relationship. A detailed description of the plant disease caused by $P$. stizolobii, and of the characteristics of this species will be reported else-

Table I. Reports of sheathed flagella in bacteria

\begin{tabular}{|c|c|c|}
\hline Bacterium & Flagellum diameter & Reference \\
\hline Bacillus brevis & $?$ & De Robertis \& Franchi (I95I) \\
\hline Vibrio metchnikovii & $270 \pm 20 \AA$ & $\begin{array}{l}\text { van Iterson (I953) } \\
\text { Follett \& Gordon (1963) } \\
\text { Glauert, Kerridge \& Horne (1963) }\end{array}$ \\
\hline Vibrio cholerae (sic) & $300 \AA$ & Das \& Chatterjee (1966) \\
\hline Vibrio eltor & $270 \pm 20 \AA$ & Follett \& Gordon (1963) \\
\hline Vibrio sp. & ? & Tweedy, Park \& Hodgkiss (1968) \\
\hline Bdellovibrio bacteriovorus & $280-290 \AA$ & $\begin{array}{l}\text { Abram \& Shilo (1967) } \\
\text { Seidler \& Starr (I968) } \\
\text { Burger, Drews \& Ladwig (1968) }\end{array}$ \\
\hline Pseudomonas rhodos & $177 \AA$ & $\begin{array}{l}\text { Lowy \& Hanson (I965) } \\
\text { Lowy (I965) }\end{array}$ \\
\hline Proteus vulgaris & $?$ & Lowy \& Hanson (1965) \\
\hline Spirillum spp. & $?$ & Lockard \& Boler (1968) \\
\hline
\end{tabular}

where. (Allen, Hayward, Halliday \& Fulcher, to be published). P. stizolobii differs from the human and animal pathogenic vibrios in which sheathed flagella have been described in having an oxidative metabolism of glucose, a negative oxidase reaction, and in failing to hydrolyse starch or gelatin. $P$. stizolobii is a short straight rod, containing refractile sudanophilic inclusions, which never exhibits the marked degree of cell curvature and of pleomorphism in old cultures which is characteristic of Vibrio (Park \& Holding, 1966). P. stizolobii is thus the first member of the genus Pseudomonas in which a sheathed flagellum of the kind observed in Vibrio and Bdellovibrio has been identified. In $P$. rhodos sheathed flagella have been reported but they are clearly different in size and organization, being more slender ( $c f$. Table I) and having a sheath consisting of two helically wound ribbons which were easily visible by negative contrast (Lowy \& Hanson, 1965); furthermore the fine structure of the core could be seen through the sheath when negative contrast methods were employed. There is therefore good reason to think that the sheath of this type is different in structure and size from those occurring in Vibrio, Bdellovibrio and $P$. stizolobii.

The value of the occurrence of sheathed flagella as a taxonomic criterion should be stressed. With the advent of improved negative contrast staining and sectioning techniques, and the more general use of electron microscopy, this is a feature of the fine structure of the bacterial cell which, like the occurrence of fimbria-like appendages, 
will be of use in the characterization and identification of bacteria. Sheathing appears to be a stable feature of Pseudomonas stizolobii since one of the cultures used, NCPPB 450 , was isolated in 1954 and had been maintained since then in various culture collections. In a survey of some Pseudomonas species for the presence of fimbria-like appendages, only the two strains of $P$. stizolobii examined in that survey possessed sheathed flagella. The remaining 20 strains representing $I 4$ species all possessed flagella of a diameter and substructure which were normal for the naked flagella of bacteria (Fuerst \& Hayward, 1969). However, a much more extensive survey for the presence of sheathed flagella in Pseudomonas is required before general conclusions can be made.

At present nothing is known about the functional significance of the sheath in motile bacteria. A comparison of the motility of Bdellovibrio, Vibrio and Pseudomonas stizolobii with the motility of polarly flagellate Gram-negative bacteria with naked flagella, or with sheathless mutants of normally sheathed bacteria, may provide information about function. The sheath may be 'protective' or be an integral part of the flagellum (Doetsch \& Hageage, 1968).

'Tubules' and 'knobs' at the distal ends of sheathed flagella were frequently seen in this study. It is not clear whether these structures are an artifact resulting from autolytic effects or the effects of chemical treatment, or whether they occur naturally as a result of a lack of synchrony between synthesis of core and sheath. The 'tubules' were always irregularly folded structures. Follett \& Gordon (I963) considered similar structures to be empty sheaths. Abram \& Shilo (1967) and Seidler \& Starr (1968) have also noted that sheath material often extends beyond the distal end of the flagellar filament. The evidence from the present study seems to confirm the general opinion that these 'tubules' represent sheath material.

It should again be emphasized that at this stage it is not possible to attribute any of the effects on the sheathed flagella seen after various treatments to particular reagents. Distal 'tubules' and delineation of core and sheath were sometimes seen in preparations which had not been treated with potassium iodide or any other reagent. The treatments were undertaken either because other workers had found similar procedures successful or because it seemed possible that they might enhance delineation of sheath and core. One might note that these qualifications may also apply to the results of treatments of sheathed flagella performed by Follett \& Gordon (1963) and Seidler \& Starr (1968).

Continuity of the outermost envelope of the cell wall with the sheath covering the flagellum has been determined in ultrathin sections of Bdellovibrio by Abram \& Shilo (I967) and by Seidler \& Starr (I968), and in Vibrio metchnikovii by Glauert, Kerridge \& Horne (1963). Sections showing a continuity with the cell wall were not obtained in this study, although it was established that the thickness of the sheath was comparable to that of the outer membrane of the cell wall. There is no reason to doubt that more favourable sections would show a continuity between these layers.

We wish to thank Mr D. Gowanlock and Mr J. Hardy of the Electron Microscope Unit, University of Queensland, for assistance in electron microscopy and interpretation of electron micrographs. One of us (J.A.F.) held a University of Queensland Honours Scholarship and a Commonwealth University Scholarship. This work was supported by an Australian Universities Commission grant. 


\section{REFERENCES}

ABram, D. \& ShILo, M. (1967). Structural features of Bdellovibrio bacteriovorus in cultures and in host-parasite mixtures. Bact. Proc. p. 4I.

Burger, A., Drews, G. \& Ladwig, R. (I968). Wirtkreis und Infektionscyclus eines neu isolierten Bdellovibrio bacteriovorus Stammes. Arch. Mikrobiol. 6r, $26 \mathbf{1}$.

Burkholder, W. H. (1957). A bacterial disease of clover and velvet beans. Phytopathology 47, 48 .

DAS, J. \& ChATterJeE, S. N. (1966). Electron microscopic studies of some ultrastructural aspects of Vibrio cholerae. Indian J. med. Res. 54, 330.

De Robertis, E. \& Franchi, C. M. (195I). Electron microscopic observations on the fine structure of bacterial flagella. Expl Cell Res. 2, 295.

Doetsch, R. N. \& HaGeaGe, G. J. (1968). Motility in procaryotic organisms: problems, points of view, and perspectives. Biol. Rev. 43, 3 I 7.

Fuerst, J. A. \& HAYWARD, A. C. (1969). Surface appendages similar to fimbriae (pili) on Pseudomonas species. J. gen. Microbiol. 58, 277.

Follett, E. A. C. \& GoRdon, J. (1963). An electron microscopic study of Vibrio flagella. J. gen. Microbiol. 32, 239.

Glauert, A. M., Kerridge, D. \& Horne, R. W. (I963). The fine structure and mode of attachment of the sheathed flagellum of Vibrio metchnikovii. J. biophys. biochem. Cytol. 18, 327.

Joys, T. M. (1968). The structure of flagella and the genetic control of flagellation in Eubacteriales. A review. Antonie van Leeuwenhoek 34, 205.

LOCKARD, V. G. \& Boler, R. K. (1968). Ultrastructure of spirilla found in the gastric mucosa of dogs. J. Cell Biol. 39, 82 a.

Lowy, J. (1965). Structure of the proximal ends of bacterial flagella. J. molec. Biol. 14, 297.

Lowy, J. \& HANSON, J. (1965). Electron microscopic studies of bacterial flagella. J. molec. Biol. xr, 293.

PARK, R. W. A. \& Holding, A. J. (1966). Identification of some common Gram-negative bacteria. Lab. Pract. 15, I124.

Rothwell, A. \& HaYward, A. C. (1964). A bacterial disease of Bougainvillea. Rhod.J. agric. Res. 2, 97.

SeIdler, R. J. \& Starr, M. P. (1968). Structure of the flagellum of Bdellovibrio bacteriovorus. J. Bact. 95, 1952.

STAPP, C. (1935). Contemporary understanding of bacterial plant-diseases and their causal organisms. Bot. Rev. I, 405 .

Tweedy, J. M., PARK, R. W. A. \& Hodgkiss, W. (1968). Evidence for the presence of fimbriae (pili) on Vibrio species. J. gen. Microbiol. 51, 235.

VAN ITERSON, W. (1953). Some remarks on the present state of our knowledge of bacterial flagellation. Symp. Citologia Batterica. 6th Int. Congr. Microbiol., Rome. pp. 24-38.

VARON, M. \& SHILo, M. (1968). Interaction of Bdellovibrio bacteriovorus and host bacteria. I. Kinetic studies of attachment and invasion of Escherichia coli by Bdellovibrio bacteriovorus. J. Bact. 95 , 744 .

\section{EXPLANATION OF PLATES}

Abbreviations used in figures: $\mathrm{T}$, distal 'tubule'; $\mathrm{K}$, distal 'knob'; $\mathrm{C}$, core; $\mathrm{S}$, sheath.

\section{Plate I}

Fig. I. Pseudomonas stizolobii strain NCPPB 450 after two $72 \mathrm{hr}$ serial subcultures in motility medium +5 serial subcultures in peptone yeast extract broth incubated at $28^{\circ}$. A single polar flagellum without visible substructure arises from the cell. Negatively stained with sodium phosphotungstate, $\mathrm{pH} 7 \cdot 0 . \times 56,000$.

Fig. 2. $P$. stizolobii strain NCPPB 450 after two $72 \mathrm{hr}$ serial subcultures in motility medium +8 serial subcultures in peptone yeast extract broth incubated at $28^{\circ}$. Several cells with single polar flagella are visible. Negatively stained with sodium phosphotungstate, $\mathrm{pH} \mathrm{7 \cdot 3.} \times 20,000$.

\section{Plate 2}

Fig. 3. $P$. stizolobii strain $0268 \mathrm{~A}$ after two $72 \mathrm{hr}$ serial subcultures in motility medium +8 serial subcultures in peptone yeast extract broth incubated at $28^{\circ}$. An enlarged portion of a sheathed flagellum (note the rounded tip). Negatively stained with sodium phosphotungstate, $\mathrm{pH} 7 \cdot 3 . \times 160,000$. 

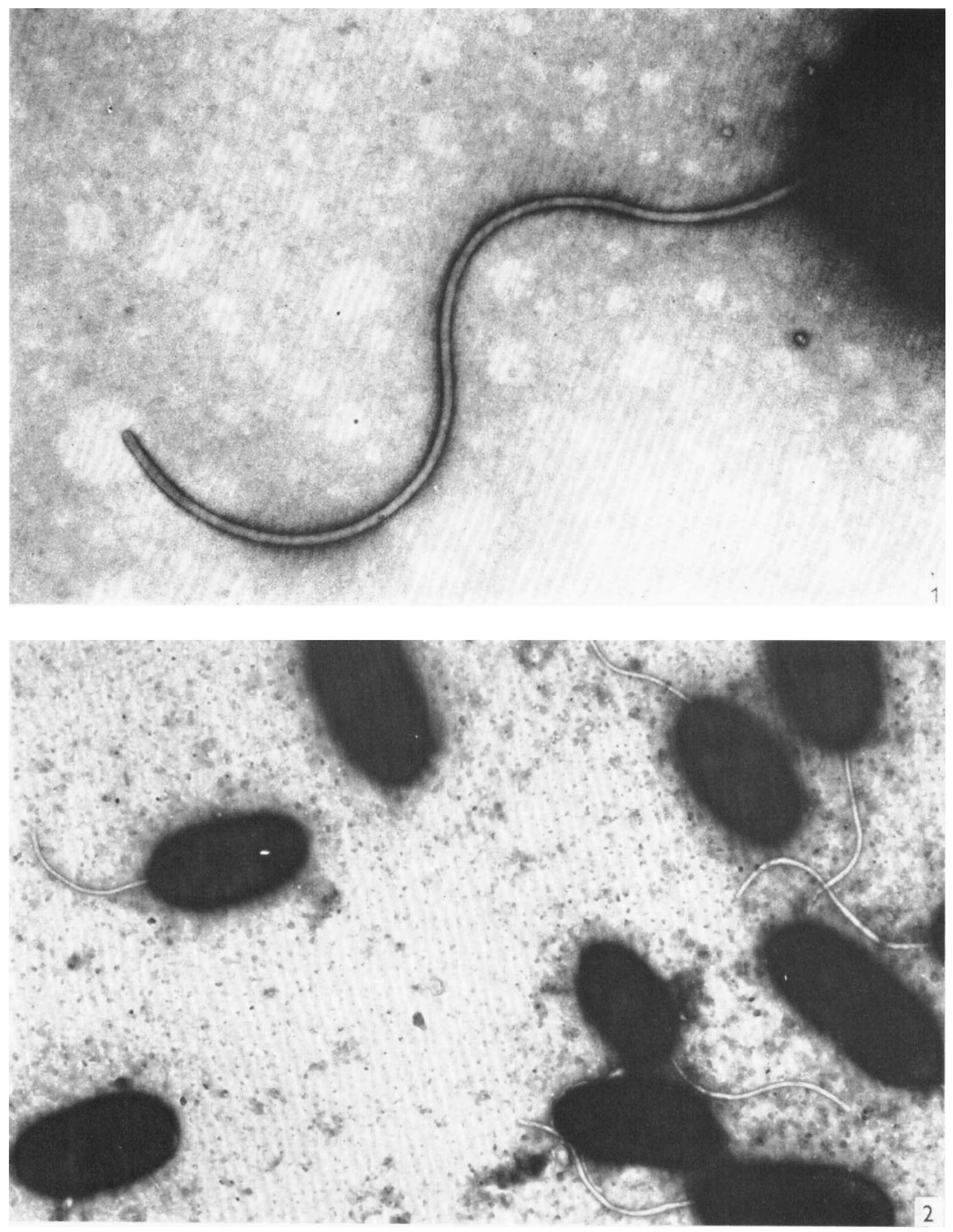
Journal of General Microbiology, Vol. 58, No. 2

Plate 2
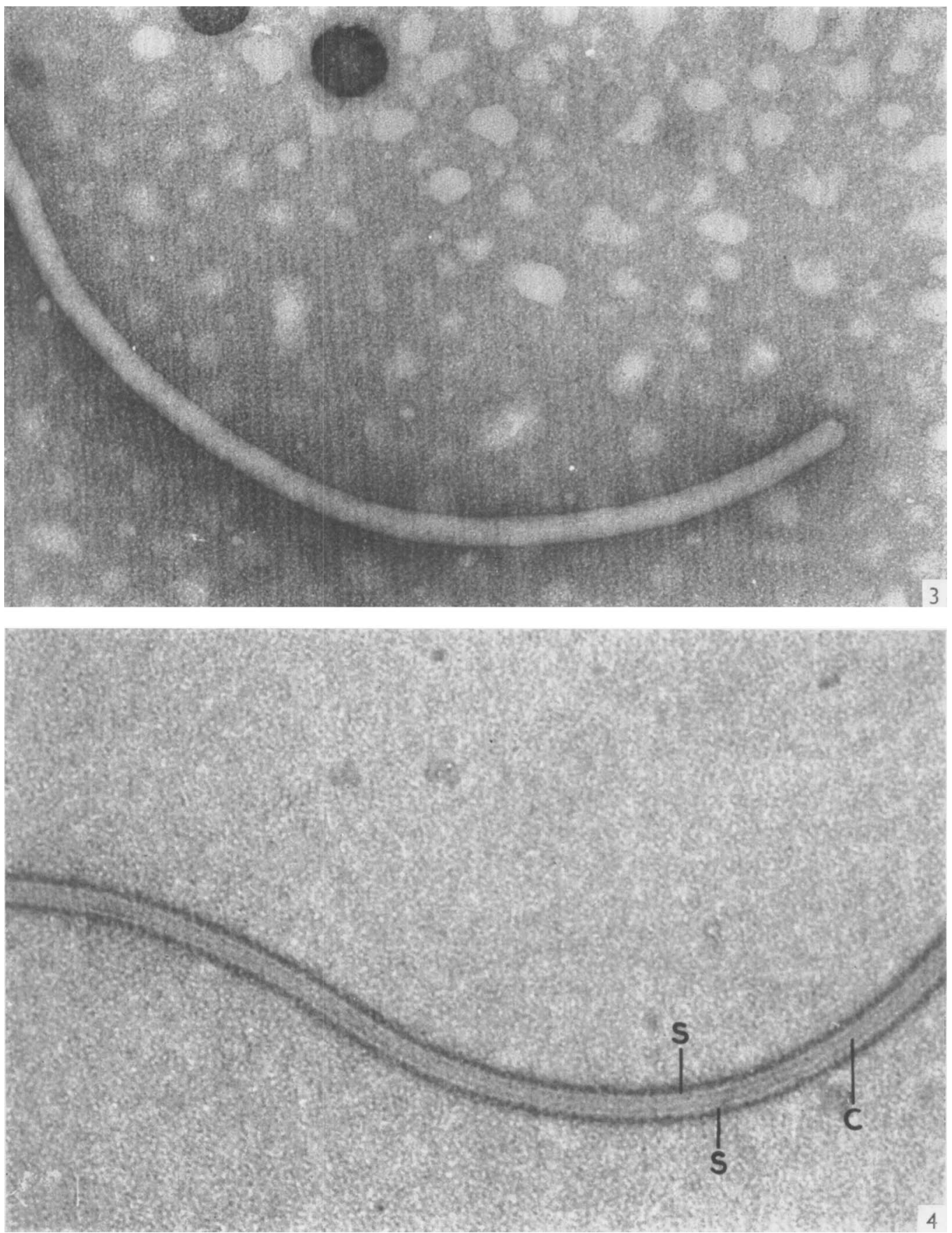

J. A. FUERST AND A. C. HAYWARD 
Journal of General Microbiology, Vol. 58, No. 2

Plate 3
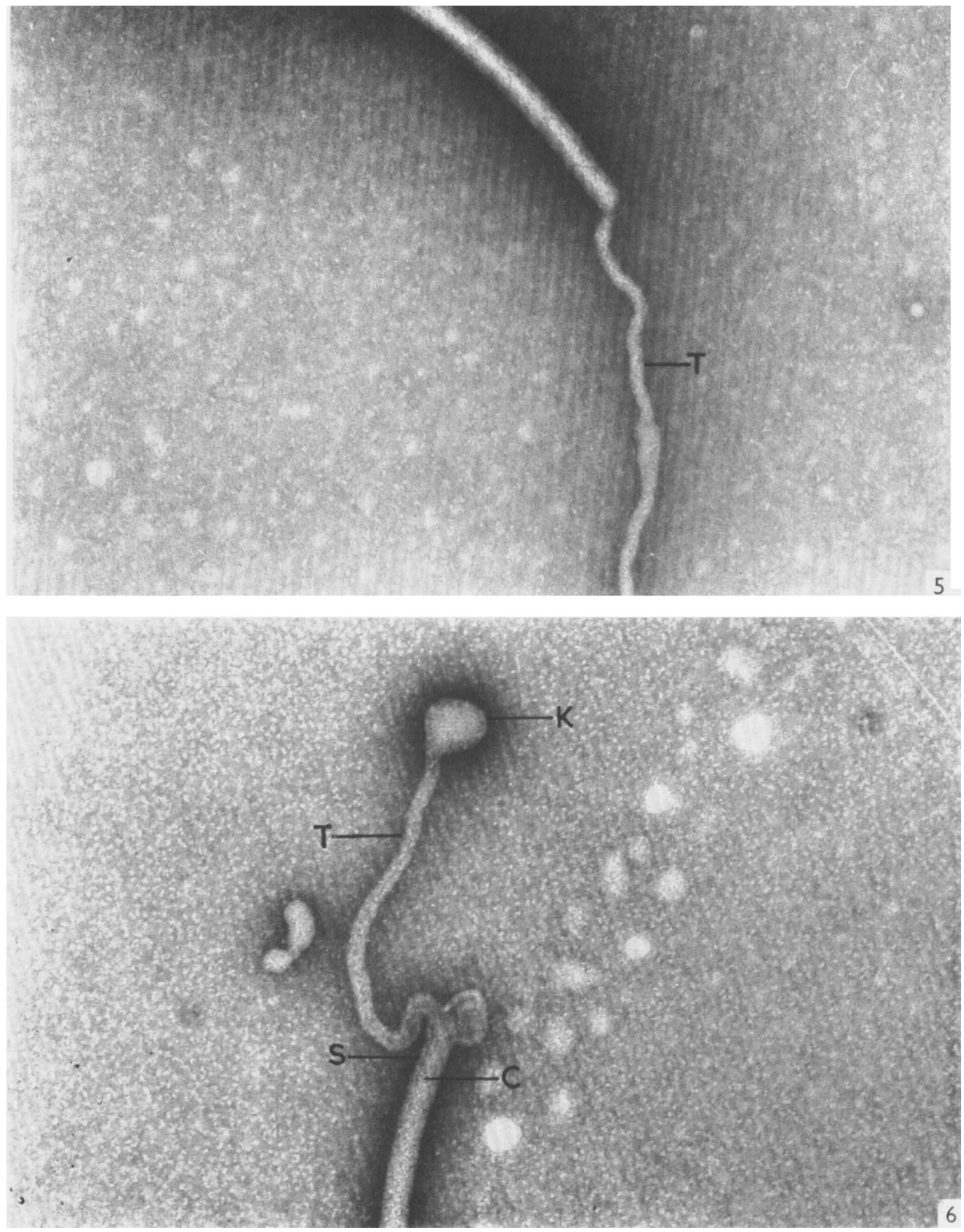

J. A. FUERST AND A. C. HAYWARD 
Journal of General Microbiology, Vol. 58, No. 2

Plate 4
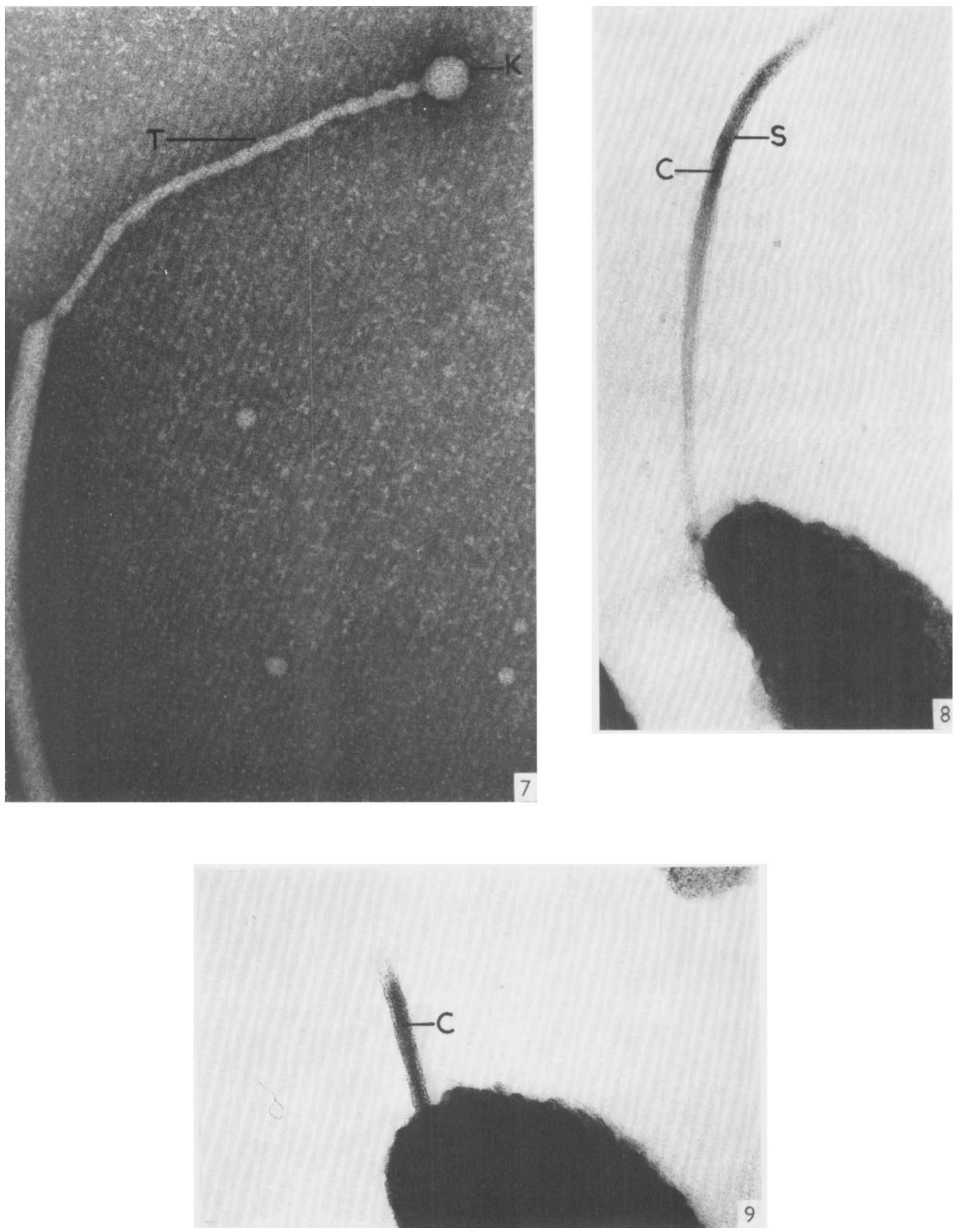

J. A. FUERST AND A. C. HAYWARD 
Fig. 4. $P$. stizolobii strain NCPPB 450 after growth for $70 \mathrm{hr}$ in peptone yeast extract broth incubated at $28^{\circ}$ followed by treatment for $10 \mathrm{sec}$. with I $\% \mathrm{KI}$. + Io sec. distilled water $+20 \mathrm{sec}$. $\mathrm{N} / \mathrm{I} O 0 \mathrm{HCl}$ $(\mathrm{pH} 2 \cdot 2)+10$ sec. distilled water. Delineation of core and sheath structure is visible. Negatively stained with sodium phosphotungstate, $\mathrm{pH} 7 \cdot 4 . \times 130,000$.

\section{Plate 3}

Fig. 5. $P$. stizolobii strain NCPPB 450 after growth for $20 \mathrm{hr}$ in glucose peptone yeast extract broth incubated at $28^{\circ}$, followed by treatment for $5 \mathrm{sec}$. with distilled water $+45 \mathrm{sec}$. $1 \mathrm{O}^{-3} \mathrm{M}-\mathrm{Na}_{2} \mathrm{EDTA}+$ $5 \mathrm{sec}$. distilled water. An irregularly folded distal 'tubule' extends from an apparently intact flagellum. Negatively stained with sodium phosphotungstate, $\mathrm{pH} 7 \cdot 4 . \times 160,000$.

Fig. 6. $P$. stizolobii strain NCPPB 450 after growth for $20 \mathrm{hr}$ in glucose peptone yeast extract broth incubated at $28^{\circ}$, followed by treatment for $5 \mathrm{sec}$. with distilled water $+12 \mathrm{sec} .0 .05 \%$ phenol $+5 \mathrm{sec}$. distilled water. Core and sheath delineation and distal 'tubule' and 'knob' are visible. Negatively stained with sodium phosphotungstate, $\mathrm{pH} 7 \% 4 . \times 160,000$.

\section{Plate 4}

Fig. 7. $P$. stizolobii strain NCPPB 450 after growth for $20 \mathrm{hr}$ in glucose peptone yeast extract broth incubated at $28^{\circ}$, followed by treatment for $5 \mathrm{sec}$. with distilled water $+15 \mathrm{sec}$. $6 \mathrm{M}$-urea $+5 \mathrm{sec}$. distilled water. A distal 'tubule' and 'knob' extend from an apparently intact flagellum. Negatively stained with sodium phosphotungstate, $\mathrm{pH}_{7} \cdot 4 . \times 160,000$.

Fig. 8. P. stizolobii strain NCPPB 450 after growth for $26 \mathrm{hr}$ in glucose peptone yeast extract broth incubated at $28^{\circ}$. Sheath and core structure is visible in the sectioned flagellum. Glutaraldehydeosmium tetroxide fixation. $\times 120,000$.

Fig. 9. P. stizolobii strain NCPPB 450 after growth for $26 \mathrm{hr}$ in glucose peptone yeast extract broth incubated at $28^{\circ}$. Sheath and core structure is visible in the sectioned flagellum. Glutaraldehydeosmium tetroxide fixation. $\times 120,000$. 